\title{
Hematopoietic Cell Transplantation after Administration of High-Dose Busulfan in Murine Globoid Cell Leukodystrophy (the Twitcher Mouse)
}

\author{
ANDREW M. YEAGER, MITSUKO SHINOHARA, ${ }^{1}$ AND CHARLOTTE SHINN
}

The Oncology Center [A.M.Y., M.S., C.S.] and the Departments of Pediatrics [A.M.Y.] and Neurology [A.M.Y.J, The Johns Hopkins University School of Medicine, Baltimore, Maryland 21205

\begin{abstract}
We evaluated the effectiveness of administration of high-dose busulfan (BU), an alkylating agent with substantial myeloablative but negligible immunosuppressive properties, on the engraftment of congenic normal bone marrow and spleen cells (hematopoietic cell transplantation; HCT) in murine galactosylceramidase deficiency (the twitcher mouse), a model of human sphingolipid storage disease. Untreated mice died with extensive demyelination and failure to thrive at a median age of $\mathbf{4 0} \mathrm{d}$ (range, 28-47; $n=51$ ). The life-span of twitcher mice given HCT at age $10 \mathrm{~d}$ after $100 \mathrm{mg} / \mathrm{kg} \mathrm{BU}$ was significantly prolonged (median, $94 \mathrm{~d}$; range, $55-140 ; n=17$ ); these animals did not develop the hindlimb paralysis seen in untreated twitchers. Histologic examination of twitcher sciatic nerves after HCT showed remyelinated areas and decreased globoid cell inclusions. Animals given HCT after conditioning with BU had both lymphoid and hematopoietic repopulation with donor cells by $90 \mathrm{~d}$ after HCT, as documented by presence of donor glucose phosphate isomerase-1A activity in blood, bone marrow, spleen, and lymph nodes. After BU and HCT, galactosylceramidase activity in livers and spleens of twitcher mice reached 45 and $80 \%$ of control, respectively; only modest elevations were observed in kidneys and lymph nodes. Hydrolase activity rose to $20 \%$ in the brains and exceeded control values in the sciatic nerves of transplanted twitcher mice, indicating entry of at least some donor-derived cells and/ or hydrolase across the blood-brain and blood-nerve barriers after BU and HCT. These observations suggest that, in gene-replacement therapy for human lysosomal storage diseases, administration of $\mathrm{BU}$ alone may be sufficient for sustained engraftment of autologous marrow cells into which the specific hydrolase gene has been inserted. (Pediatr Res 29: 302-305, 1991)
\end{abstract}

\section{Abbreviations}

BMT, bone marrow transplantation BU, busulfan

GPI-1, glucose phosphate isomerase-1

GPI-1A, A isoenzyme of GPI-1

Received August 7, 1990; accepted October 16, 1990.

Correspondence and reprint requests: Andrew M. Yeager, M.D., Room 3-127, The Johns Hopkins Oncology Center, Baltimore, MD 21205.

Supported by Grants No. R01 NS24097 and S07 RR05378, National Institutes of Health, Department of Health and Human Services, Bethesda, MD, by Basil O'Connor Starter Research Grant No. 5-485 from the March of Dimes Birth Defects Foundation, White Plains, NY, and by grants from The Children's Cancer Foundation, Inc., Baltimore, MD, The National Children's Cancer Society, Inc., Edwardsville, IL, and The United Leukodystrophy Foundation, Sycamore, IL.

'Current address: Department of Pharmacology, Osaka Dental University, Osaka 540, Japan.
GPI-1B, B isoenzyme of GPI-1

HCT, hematopoietic cell transplantation

TBI, total body irradiation

The human sphingolipidoses are causes by deficiencies of specific lysosomal hydrolases and are associated with significant morbidity and mortality. It has been suggested that allogeneic BMT, which repopulates the hematopoietic, lymphoid, and reticuloendothelial systems with normal donor-derived cells, may be therapeutic in patients with storage diseases by providing a self-renewing cellular source of exogenous hydrolase $(1,2)$. Despite encouraging preliminary clinical reports (3-7), the definitive therapeutic role of allogeneic BMT in human sphingolipidoses remains controversial

Comprehensive studies in animal models of lysosomal hydrolase deficiency states may provide instructive preclinical information on the application of BMT to these conditions (8-12). For example, HCT (transplantation of syngeneic bone marrow and spleen cells) leads to prolonged survival $(9,10)$ and neuropathologic (9), neurophysiologic (13), and biochemical (10,14) improvement in the "twitcher" mouse, an authentic model of the human sphingolipidosis Krabbe disease (galactosylceramidase deficiency; globoid cell leukodystrophy) (15-17). To provide both myeloablation and immunosuppression of the recipient for satisfactory engraftment of enzymatically normal donor stem cells, pretransplant conditioning with TBI has been used in animal HCT or BMT studies (8-12) and in some reports of allogeneic BMT for human sphingolipidoses $(3,5,7)$.

The future therapeutic approach for human lysosomal hydrolase deficiency states will most likely entail infusion of autologous marrow stem cells into which the cloned functional hydrolase gene has been inserted (18). The optimal pretransplant conditioning regimen that will allow engraftment and proliferation of such genetically modified autologous stem cells is unknown; in theory, myeloablation without immunosuppression may be satisfactory. BU is a chemotherapeutic alkylating agent that is highly toxic to hematopoietic stem cells $(19,20)$. Unlike TBI or highdose cyclophosphamide, BU lacks immunosuppressive activity $(20,21)$ and would therefore appear to be an ideal preparative agent for autografting of genetically modified marrow cells in storage disease.

In this report, we describe the effectiveness of high-dose BU as a myeloablative preparative agent for congenic HCT in the twitcher model of galactosylceramidase deficiency. We compared the effects of HCT after BU administration on the survival, neuropathologic and biochemical alterations, and lymphohematopoietic reconstitution in this murine sphingolipidosis. 


\section{MATERIALS AND METHODS}

Mice. Breeding pairs of congenic C57BL/6 mice that were heterozygous for the twitcher mutation $(+/$ twi) or homozygous for GPI-1A were obtained from the Jackson Laboratory, Bar Harbor, ME. Normally, the C57BL/6 strain, including the twitcher mutation, is homozygous for the codominant GPI-1B (22). Hematopoietic cell transplants were carried out from congenic GPI-1A donors (which have normal tissue activity of galactosylceramidase) into recipient GPI-1B twitcher offspring or normal littermates; engraftment was assessed by electrophoretic analysis of 5- to $10-\mu \mathrm{L}$ blood samples from recipient mice to detect donor GPI-1A isoenzyme (23). All animals were housed in sterilized shoebox-type plastic cages and given sterilized standard laboratory food and tap water ad libitum. Litters were housed with sire and dam until time of weaning. Galactosylceramidase activity in samples of homogenized clipped tail tips of 7-d-old offspring (24) identified their genetic status (twitcher, heterozygous carrier, or normal). Behavioral observations provided clinical identification of affected (twi/twi) offspring, in which the onset of neurologic symptoms occurs at approximately $21 \mathrm{~d}$ of age (15-17). This study was reviewed and approved by the Animal Care and Use Committee of The Johns Hopkins Medical Institutions, and mice were maintained according to National Institutes of Health Guidelines for Humane Care of Laboratory Animals.

HCT procedure. BU (Aldrich Chemical Co., Milwaukee, WI) was solubilized in acetone and suspended in $1 \%$ carboxymethylcellulose (Sigma Chemical Co., St. Louis, MO) at a final BU concentration of $3.0 \mathrm{mg} / \mathrm{mL}$. Cohorts of twitcher mice and control littermates received single intraperitoneal injections of BU $(100 \mathrm{mg} / \mathrm{kg} / \mathrm{mouse})$ at age $9 \mathrm{~d}$, followed by HCT $24 \mathrm{~h}$ later. Congenic normal 6- to 8-wk-old GPI-1A mice were killed by lethal carbon dioxide narcosis, and single-cell suspensions of donor bone marrow were prepared by flushing the cavities of humeri and femora into Hanks' balanced salt solution (GIBCO, Grand Island, NY) and repetitive gentle pipetting of marrow plugs to disperse the clumps of cells. Donor spleens were gently teased with forceps through a fine stainless steel wire mesh (Newark Wire Cloth Co., Newark, NJ) into Hanks' balanced salt solution, and a single-cell suspension was obtained by repetitive pipetting with a sterile Pasteur pipette. To insure sufficient congenic donor cells for engraftment, each recipient mouse was given $10-15 \times 10^{6}$ bone marrow cells and $35-50 \times 10^{6}$ spleen cells by intraperitoneal injection with a tuberculin syringe and a 26- or 30-gauge needle. For 10 to $14 \mathrm{~d}$ after HCT, mice were provided with acidified drinking water $(\mathrm{pH} \mathrm{2.0-2.5)}$ to which was added prophylactic neomycin (final concentration $500 \mu \mathrm{g} /$ $\mathrm{mL}$ ), polymyxin B (final concentration $13 \mu \mathrm{g} / \mathrm{mL}$ ), and trimethoprim-sulfamethoxazole (final concentration as trimethoprim $100 \mu \mathrm{g} / \mathrm{mL}$ ). At selected times after HCT, blood samples were obtained from the retroorbital plexus of recipient animals, and electrophoretic determination of GPI-1 isoenzymes was carried out (23) to assess engraftment.

Biochemical assays. At selected times after HCT, animals were deeply anesthetized with methoxyflurane. After blood samples were obtained by direct cardiac puncture, the animals were perfused with normal saline to remove contaminating blood from organs and tissues. Samples of spleens and lymph nodes were prepared for GPI-1 determination by homogenization in distilled water with a Dounce micro-homogenizer type tissue grinder (Wheaton Glass Co., Vineland, NJ). Samples of blood, bone marrow, lymph nodes, and spleens of transplanted twitcher mice were analyzed for GPI-1 isozymes by electrophoresis on cellulose acetate plates (Titan III; Helena Laboratories, Helena, MT) in a microelectrophoresis chamber (Helena) and staining with phenazine-thiazol blue in an agar overlay, according to published methods $(9,23)$. This technique demonstrates a discrete band of activity for each GPI-1 isoenzyme (A or B). Samples of tail tips, approximately $1 \mathrm{~cm}$ long, were obtained from 7-d- old mice and homogenized on $1 \mathrm{~mL}$ of distilled water using a microhomogenizer. Aqueous homogenates of these tail tips and of samples of kidney, cervical lymph node, liver, spleen, brain, and sciatic nerve from untreated and saline-perfused HCTtreated twitcher mice and from control normal littermates were tested for total protein content with the spectrophotometric method of Lowry et al. (25), and activity of galactosylceramidase (EC 3.2.1.46) in these samples was assayed at $\mathrm{pH} 3.8$ using tritiated galactosylceramide as the substrate $(24,26,27)$. Enzyme activity was expressed as a function of protein content in each sample.

Neuropathologic studies. At selected times after HCT, twitcher mice were deeply anesthetized with methoxyflurane and perfused through the ascending aorta with a rinse of normal saline solution and then with $5 \%$ glutaraldehyde (28). The sciatic nerves and nerve roots were then dissected, and $3.0-\mathrm{mm}$ segments of the nerves were dehydrated in graded alcohols, embedded in Epon, and cut in $1 \mu \mathrm{m}$-thick transverse sections. The sections were stained with toluidine blue and examined with light microscopy to determine qualitatively the integrity of myelin sheaths and the degree of remyelination in the posttransplant period.

Statistical analysis. Routine statistical calculations were performed with a hand-held calculator (Texas Instruments, Inc., Lubbock, TX). Statistical evaluation of the data was carried out with the two-sample $t$ and Wilcoxon rank-sum tests, using a personal microcomputer (IBM Corp., Armonk, NY) and software packages developed by the Biostatistics and Information Systems Division of The Johns Hopkins Oncology Center.

\section{RESULTS}

Effects of HCT on survival and neuropathology of twitcher mice. Untreated twitcher mice appeared normal for the first 3 wk of life, then developed truncal tremor, hindlimb paralysis, and impairment of gait, foraging, and grooming behaviors. These animals died with progressive neurodegeneration and failure to thrive at a median of $40 \mathrm{~d}$ of age (range, 28-47) (Table 1). The survival of twitcher mice given high-dose BU followed by HCT from congenic normal GPI-1A donors at age $10 \mathrm{~d}$ was significantly prolonged relative to that of untreated mice: the median survival of transplanted twitcher mice was $94 \mathrm{~d}$ (range, 55-140) (Table 1). Twitcher recipients of HCT had improved gait and did not develop the characteristic hindlimb paralysis seen in untreated twitchers. Histopathologic examination of sciatic nerves from untreated preterminal twitcher mice showed preservation of axons, infiltration with mononuclear cells (some of which contained characteristic globoid cell inclusions), perineurial edema, and total loss of myelin sheaths, as previously reported (29). In contrast, sciatic nerves from 100-d-old BU-treated animals (90 d after HCT) showed areas of remyelinated axons, decreased edema and mononuclear cells, and only rare inclusions (Fig. 1)

Engraftment and lymphohematopoietic repopulation after $H C T$. Donor-derived GPI-1A activity was first detected in the blood of twitcher mice 14-21 d after HCT following high-dose BU, along with residual recipient GPI-1B isoenzyme. Six to seven wk after transplant, only donor GPI-1A activity was present in the blood. Despite its lack of immediate lympholytic or

Table 1. Effect of high-dose BU and HCT on survival of twitcher mice

\begin{tabular}{lcl}
\hline \multicolumn{1}{c}{ Treatment } & No. of animals & $\begin{array}{c}\text { Median survival } \\
\text { (d) (range) }\end{array}$ \\
\hline None & 51 & $40(28-47)$ \\
BU $(100 \mathrm{mg} / \mathrm{kg}$ intraperitoneally) & 17 & $94(55-140) \dagger$ \\
\hline
\end{tabular}

*Animals received $\mathrm{BU}(100 \mathrm{mg} / \mathrm{kg})$ at age $9 \mathrm{~d}$ and an intraperitoneal injection of $10-15 \times 10^{6}$ bone marrow and $35-50 \times 10^{6}$ spleen cells from GPI-1 A congenic donors $24 \mathrm{~h}$ later.

$\dagger p<0.01 v s$ control (Wilcoxon rank-sum test). 


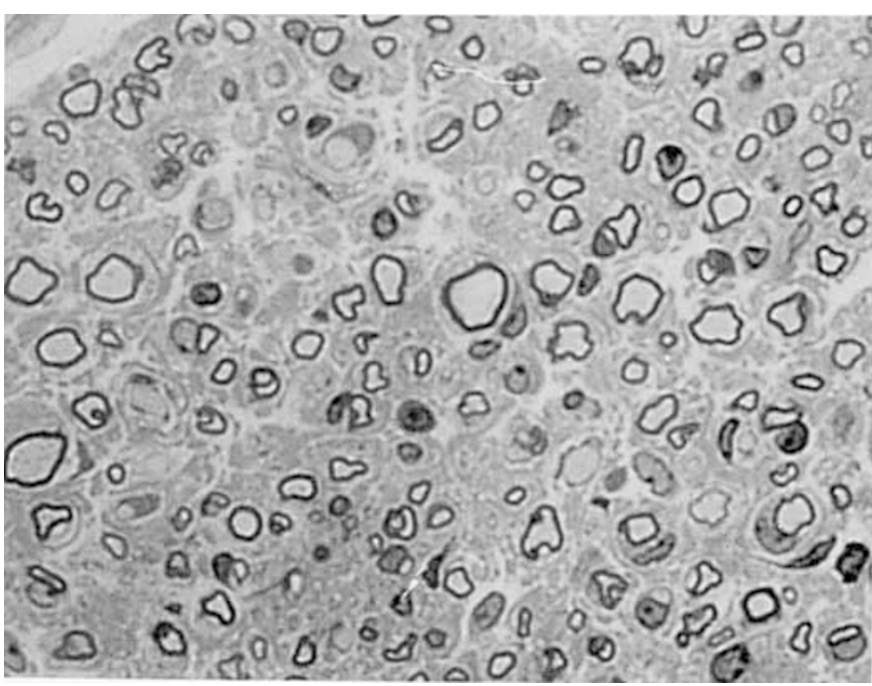

Fig. 1. Photomicrograph of sciatic nerve from 100-d-old twitcher mouse, $90 \mathrm{~d}$ after administration of high-dose BU and HCT from enzymatically normal congenic donors. Areas of remyelination and intact myelin sheaths are present, as indicated by the darkly staining regions surrounding the axons. Toluidine blue stain; $\times 693$ magnification.

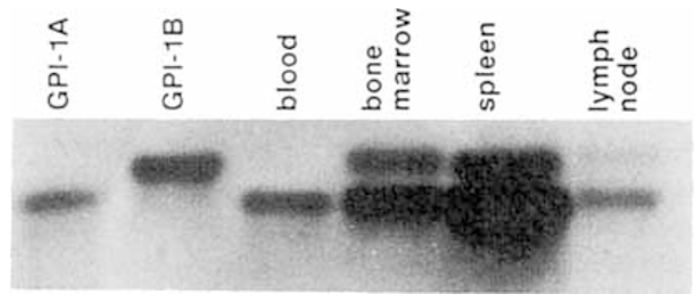

Fig. 2. Electrophoretic pattern of GPI-1 isozymes in twitcher mice after HCT from normal congenic GPI-1 A donors after high-dose intraperitoneal BU. Samples were obtained from 100-d-old animals $(90 \mathrm{~d}$ after HCT). After BU conditioning, both lymphoid and hematopoietic tissues were repopulated with donor GPI-1A cells. Residual GPI-1B activity represents recipient nonlymphohematopoietic tissue (e.g. marrow stromal cells; splenic or lymph node capsule).

immunosuppressive effects, BU administration in preparation for HCT was effective for repopulation of recipient lymphoid tissue with donor cells as well. Lymph nodes obtained from transplanted 100-d-old twitcher mice ( $90 \mathrm{~d}$ after HCT) demonstrated donor GPI-1A activity (Fig. 2). Bone marrow and spleen, which contain both lymphoid and hematopoietic cells in the mouse, also had significant donor GPI activity after BU and HCT (Fig. 2). Residual recipient GPI-1B isoenzyme in these samples was most likely due to the presence of nonlymphohe- matopoietic cells (e.g. splenic or lymph node capsule; bone marrow stroma), inasmuch as mononuclear cell fractions isolated after centrifugation of bone marrow and spleen cell suspensions on Ficoll-diatrizoate gradients demonstrated only donor GPI-1A isoenzyme. These electrophoretic patterns were consistently observed in 130-d-old transplanted twitcher mice and in normal control littermates killed at least $1 \mathrm{y}$ after transplant, indicating that BU and HCT provides sustained engraftment of congenic donor cells without evidence for attrition of the donor graft or of autologous lymphohematopoietic recovery.

Galactosylceramidase activity after HCT (Table 2). Levels of galactosylceramidase in tissues of untreated twitcher mice ranged from only 4 to $20 \%$ of values in control littermates; by 3 mo after HCT following high-dose BU, donor-derived enzyme was detected in most tissues. Galactosylceramidase levels in kidneys of transplanted twitcher mice were not significantly different from values in untreated affected animals and increased only modestly in lymph nodes. In contrast, galactosylceramidase in livers and spleens of BU-conditioned twitcher HCT recipients rose to 45 and $80 \%$ of control, respectively, representing 7- to 9fold elevations of enzyme activity in untreated twitchers. Highdose BU and HCT also provided enzyme replacement in both the central and peripheral nervous systems of twitcher mice, even though no specific techniques were used to disrupt the bloodbrain or blood-nerve barrier. Three mo after transplant, galactosylceramidase activity in twitcher brains increased significantly to $20 \%$ of control, approximately five times the values in untreated twitcher mice. The mean enzyme levels in the sciatic nerves of HCT-treated twitchers exceeded normal, representing a 30 -fold increase over galactosylceramidase activity in untreated affected mice.

\section{DISCUSSION}

In this demyelinating murine sphingolipidosis, pre-HCT myeloablative conditioning with high-dose BU leads to sustained engraftment of both lymphoid and hematopoietic congenic donor cells, even though BU is not immunosuppressive. The similar prolongation of survival, histopathologic improvement, and biochemical correction in twitcher mice given HCT after treatment with either high-dose BU or TBI strongly suggest that the favorable effects of HCT in this lysosomal storage disease model are attributable primarily to engraftment of enzymatically normal cells and not necessarily to effects of the pretransplant regimen on immune function or integrity of organs or tissues.

Although HCT after high-dose BU provides donor-derived galactosylceramidase in most tissues of twitcher mice, enzyme levels in the kidney remained low, as seen after HCT with TBI conditioning $(10,14)$. This observation is consistent with the absence in the kidney of significant lymphoid, hematopoietic, or reticuloendothelial cells, which are repopulated with donor cells after HCT. Furthermore, although this study did not examine

Table 2. Effect of HCT after high-dose BU on galactosylceramidase activity in tissues of twitcher mice*

\begin{tabular}{llcc}
\hline & \multicolumn{2}{c}{ Enzyme activity (nmol substrate cleaved/h/mg protein) } \\
\cline { 2 - 4 } Tissue & Normal controls & Untreated twitchers & Transplanted twitchers \\
\hline Kidney & $1.063 \pm 0.029(4) \dagger$ & $0.048 \pm 0.019(3)$ & $0.085 \pm 0.026(3)$ \\
Lymph node & $1.087 \pm 0.243(3) \dagger$ & $0.192 \pm 0.037(3)$ & $0.307 \pm 0.098(3)$ \\
Liver & $0.365 \pm 0.090(4)$ & $0.025 \pm 0.007(3)$ & $0.166 \pm 0.010(3) \ddagger$ \\
Spleen & $1.357 \pm 0.353(3)$ & $0.122 \pm 0.038(3)$ & $1.084 \pm 0.169(3) \S$ \\
Brain & $0.242 \pm 0.092(4)$ & $0.009 \pm 0.011(3)$ & $0.049 \pm 0.006(3) \|$ \\
Sciatic nerve & $0.408 \pm 0.127(4)$ & $0.024 \pm 0.009(3)$ & $0.721 \pm 0.093(3) \S$ \\
\hline
\end{tabular}

${ }^{*}$ Normal controls and untreated twitcher mice were killed at $40 \mathrm{~d}$ of age and transplanted twitcher mice were killed at age $100 \mathrm{~d}(90 \mathrm{~d}$ after HCT). Numbers in parentheses indicate the number of animals studied; the mean enzyme activity \pm SEM is shown.

$\dagger p<0.05$ when compared with enzyme activity in either untreated or transplanted twitcher mice (two-sample $t$ test).

$\ddagger p<0.05$ compared with enzyme activity in untreated twitcher mice.

$\S p<0.001$ compared with enzyme activity in untreated twitcher mice.

$\| p<0.01$ compared with enzyme activity in untreated twitcher mice. 
the effects of BU and HCT on levels of psychosine, the major toxic metabolite in globoid cell leukodystrophy, this compound remains extremely high in renal tissue after TBI and HCT (14).

The appearance of hydrolase in the twitcher nervous system after BU and HCT is encouraging and indicates at least some entry of donor-derived enzyme and/or mononuclear cells across the blood-brain and blood-nerve barriers. After TBI and HCT, galactosylceramidase is also detected in neural tissues, although the degree of replacement in the CNS is variable $(10,14)$. Donor monocytes gradually appear in the brains of TBI-treated twitcher HCT recipients (30); similar immunohistochemical analyses could not be conducted in the congenic HCT experiments reported here, but it is possible that the same cellular repopulation also occurs in the CNS after BU-HCT and accounts for the increased enzyme levels. Because some qualitative studies suggest that recipient globoid cells gradually decrease after HCT in the CNS of TBI-treated twitcher mice (30), quantitative assessment of globoid cell alterations in the brains of BU-conditioned twitcher HCT recipients might also be instructive.

Psychosine accumulation in twitcher mice leads to loss of oligodendroglia and Schwann cells and thus to progressive demyelination. In twitcher sciatic nerves, psychosine is strikingly elevated despite favorable effects of TBI and HCT on its levels in the CNS (14) and appearance of hydrolase in peripheral nerves (10). After BU and HCT, the increased galactosylceramidase in twitcher nerves is substantially greater than that reported after TBI and HCT (14) (30- versus 6-fold, respectively). Studies are in progress to determine whether HCT after BU alters tissue psychosine levels in twitcher mice.

Both immunosuppression and myeloablation, as provided by TBI, are required for engraftment of allogeneic marrow (31). Elimination of pre-BMT TBI may reduce the risk of opportunistic infections due to the profound immunodeficiency that results from TBI and BMT (32) and may circumvent TBIassociated toxicity (e.g. endocrine, pulmonary) (33). Conditioning with TBI has been used for transplantation of syngeneic murine hematopoietic stem cells modified by retroviral-mediated gene transfer (34); however, because immunologic rejection of genetically modified syngeneic or autologous marrow cells is unlikely, myeloablation alone may be sufficient. Our observations in this congenic HCT model suggest that high-dose BU may be an effective preparative regimen for the therapeutic administration of autologous marrow-derived stem cells, into which the cloned hydrolase gene has been inserted, in children with lysosomal storage diseases.

Acknowledgments. The authors thank Drs. Yasuo Kishimoto, Hugo Moser, and George Santos for their constructive criticism of these studies and this manuscript. Susan Brennan provided expert and conscientious technical assistance.

\section{REFERENCES}

1. Hobbs JR 1981 Bone marrow transplantation for inborn errors. Lancet 2:735739

2. Parkman R 1986 The application of bone marrow transplantation to the treatment of genetic disorders. Science 232:1373-1378

3. Bayever E, Ladisch S, Philippart M, Brill N, Nuwer M, Sparkes RS, Feig S 1985 Bone marrow transplantation for metachromatic leukodystrophy. Lancet $2: 471-473$

4. Rappeport JM, Ginns EI 1984 Bone marrow transplantation in severe Gaucher's disease. N Engl J Med 311:84-88

5. Lundgren G, Eriksson A, Groth C-G, Gahrton G, Lonnqvist B, Myrenfors P, Nilsson O, Ringden O, Sundelin P. Svennerholm L 1984 Bone marrow transplantation in juvenile Gaucher's disease. Exp Hematol 12 (suppl 15):99
6. Krivit W, Lipton ME. Lockman LA. Tsai M. Dyck PJ, Smith S, Ramsay NK Kersey J 1987 Prevention of deterioration in metachromatic leukodystrophy by bone marrow transplantation. Am J Med Sci 294:80-85

7. Ringden O, Groth C-G, Erikson A, Backman L, Granqvist S, Mansson JE, Svennerholm L 1988 Long-term follow-up of the first successful bone marrow transplantation in Gaucher disease. Transplantation 46:66-70

8. Gasper PW, Thrall MA, Wenger DA, Macy DW, Ham L, Dornsife RE, McBiles K, Quackenbush SL, Kesel ML. Gillette EL 1984 Correction of feline arylsulphatase $\mathrm{B}$ deficiency (mucopolysaccharidosis type VI) by bone marrow transplantation. Nature 312:467-469

9. Yeager AM, Brennan S. Tiffany C, Moser HW. Santos GW 1984 Prolonged survival and remyelination after hematopoietic cell transplantation in the twitcher mouse. Science 225:1052-1054

10. Hoogerbrugge PM. Poorthuis BJHM. Romme AE. van de Kamp JJ, Wagemaker G, van Bekkum DW 1988 Effect of bone marrow transplantation on enzyme levels and clinical course in the neurologically affected twitcher mouse. J Clin Invest 81:1790-1794

11. Taylor RM. Farrow BRH, Stewart GJ, Healy PJ. Tiver K 1988 The clinical effects of lysosomal enzyme replacement by bone marrow transplantation after total lymphoid irradiation on neurologic disease in fucosidase deficient dogs. Trans Proc 20:89-93

12. Shull RM, Brieder MA, Constantopoulos GC 1988 Long-term neurological effects of bone marrow transplantation in a canine lysosomal storage disease. Pediatr Res 24:347-352

13. Toyoshima E. Yeager AM. Brennan S. Santos GW, Moser HW, Mayer RF 1986 Nerve conduction studies in the twitcher mouse. J Neurol Sci 74:307318

14. Ichioka T, Kishimoto Y, Brennan S. Santos GW, Yeager AM 1987 Hematopoietic cell transplantation in murine globoid cell leukodystrophy (the twitcher mouse): effects on levels of galactosylceramidase, psychosine, and galactocerebrosides. Proc Natl Acad Sci USA 84:4259-4263

15. Suzuki K. Suzuki Y 1983 The twitcher mouse: a model of human globoid cell leukodystrophy (Krabbe's disease). Am J Pathol 111:394-397

16. Duchen LW. Eicher EM. Jacobs JM. Scaravilli F. Texeira F 1980 Hereditary leucodystrophy in the mouse: the new mutant twitcher. Brain 103:695-710

17. Kobayashi $\Upsilon$, Yamanaka T, Jacobs JM, Texeira F. Suzuki K 1980 The twitcher mouse: an enzymatically authentic model of human globoid cell leukodystrophy (Krabbe disease). Brain Res 202:479-483

18. Anderson WF 1984 Prospects for human gene therapy. Science 226:401-409

19. Dunn CDR 1974 The chemical and biological properties of busulphan. Exp Hematol 2:101-117

20. Santos GW, Tutschka PJ 1974 Effect of busulfan on antibody production and skin allograft survival in the rat. J Natl Cancer Inst 53:1775-1780

21. Tutschka PJ, Santos GW 1977 Bone marrow transplantation in the busulfantreated rat. Transplantation 24: 52-62

22. DeLorenzo RJ. Ruddle FH 1969 Genetic control of two electrophoretic variants of glucosephosphate isomerase in the mouse (Mus musculus). Biochem Genet 3:151-162

23. Eicher EM, Washburn LL 1978 Assignment of genes to regions of mouse chromosomes. Proc Natl Acad Sci USA 75:946-950

24. Kobayashi T. Nagara H, Suzuki Ki, Suzuki Ku, 1982 The twitcher mouse: determinations of genetic status by galactosylceramidase assays on clipped tail. Biochem Med 27:8-14

25. Lowry OH, Rosebrough NJ, Farr AL, Randall RJ 1951 Protein measurement with the Folin phenol reagent. J Biol Chem 193:265-275

26. Radin NS 1972 Labeled galactosylceramide and lactosylceramide. Methods Enzymol 28(B):300-306

27. Suzuki K 1978 Enzymic diagnosis of sphingolipidoses. Methods Enzymol 50(C):456-458

28. Griffin JW, Price DL 1981 Demyelination in experimental $\beta$-iminodipropionitrile and hexacarbon ncuropathies: evidence for an axonal influence. Lab Invest 45:130-141

29. Jacobs JM, Scaravilli F. DeAranda FT 1982 The pathogenesis of globoid cell leukodystrophy in peripheral nerve of the mouse mutant twitcher. J Neurol Sci 55:285-304

30. Hoogerbrugge PM. Suzuki K. Suzuki K, Poorthuis BJHM, Kobayashi T Wagemaker G, van Bekkum DW 1988 Donor-derived cells in the central nervous system of twitcher mice after bone marrow transplantation. Science 239: $1035-1038$

31. Santos GW 1974 Immunosuppression for clinical marrow transplantation Semin Hematol 11:341-351

32. O'Reilly RJ 1983 Allogeneic bone marrow transplantation: current status and future directions. Blood 62:941-961

33. Deeg HJ, Storb R. Thomas ED 1984 Bone marrow transplantation: a review of delayed complications. Br J Haematol 57:185-208

34. Williams DA, Lemischka IR, Nathan DG, Mulligan RC 1984 Introduction of new genetic material into pluripotent haematopoietic stem cells of the mouse. Nature 310:476-480 